\title{
Effects of a loading dose regimen of three infusions of chimeric monoclonal antibody to tumour necrosis factor $\alpha$ (infliximab) in spondyloarthropathy: an open pilot study
}

Filip Van den Bosch, Elli Kruithof, Dominique Baeten, Filip De Keyser, Herman Mielants, Eric M Veys

\begin{abstract}
Objective-To evaluate the efficacy and safety of a loading dose regimen of three intravenous infusions with infliximab in patients with active spondyloarthropathy. Methods-A monocentre, open-label pilot study of 21 patients with different subtypes of spondyloarthropathy was conducted. Treatment resistant patients with active disease (fulfilling inclusion criteria) received three infusions of $5 \mathrm{mg} / \mathrm{kg}$ infliximab (at weeks 0, 2, and 6). Standard clinical assessments were performed at baseline, and on days 3,7 , and 14 , and from then on every two weeks. In patients who fulfilled criteria for ankylosing spondylitis, axial assessment was performed at baseline and on days 14, 42, and 84.
\end{abstract}

Results-In all global assessments (visual analogue scale of patient global assessment, patient pain assessment, doctor global assessment), erythrocyte sedimentation rate, and $\mathrm{C}$ reactive protein, a highly significant decrease could be seen already at day 3 (compared with baseline), which was maintained up to day 84 . In patients with peripheral disease $(n=18)$, tender and swollen joint count significantly decreased. In patients with axial disease $(n=11)$, functional and disease activity indices significantly improved. Moreover in eight patients with psoriatic arthritis a significant decrease of the psoriasis area and severity index was observed. The treatment was well tolerated in all patients; no significant adverse events were seen.

Conclusion-In this open-label pilot study of a loading dose regimen of three infusions of chimeric monoclonal antibody to tumour necrosis factor $\alpha$ in patients with active spondyloarthropathy, there was a fast and significant improvement of axial and peripheral articular manifestations, without major adverse experiences.

(Ann Rheum Dis 2000;59:428-433)

The spondyloarthropathies $(\mathrm{SpA})$ are a group of related disorders with common clinical, biological, and genetic characteristics. ${ }^{1}$ Entities belonging to this group are ankylosing spondylitis, reactive arthritis, psoriatic arthritis, inflammatory bowel disease, some forms of juvenile chronic arthritis, and acute anterior uveitis. Over recent years, there has been a specific focus on the relation between subclinical gut inflammation in patients with $\mathrm{SpA}$ and joint disease. The presence of subclinical gut inflammation in patients with SpA has been confirmed by different groups and ranges from 25 to $75 \%$, depending upon the type of SpA. ${ }^{2} \mathrm{~A}$ fraction of these patients (SpA with histological evidence of chronic gut inflammation) develop clinically overt Crohn's disease at a five years' follow up. ${ }^{3}$ In repeat ileocolonoscopy studies clinical remission of articular symptoms was consistently associated with normalisation of gut histology, whereas persistence of locomotor inflammation was usually associated with persistence of gut inflammation. ${ }^{5}$ Furthermore, it has been found that treatments such as sulfasalazine have a beneficial effect on gastrointestinal and (peripheral) articular symptoms. ${ }^{6-8}$

Infliximab (Remicade, Centocor) is a chimeric anti-tumour necrosis factor $\alpha$ (anti$\mathrm{TNF} \alpha$ ) monoclonal IgG1 antibody, neutralising the soluble cytokine and blocking the membrane bound cytokine. ${ }^{9}$ An open-label trial in patients with active Crohn's disease despite steroid treatment, reported clinical remission with endoscopic healing of mucosal ulcers after a single intravenous dose. ${ }^{10}$ The first multicentre, randomised, double blind, placebo controlled trial included patients with moderate to severe Crohn's disease. ${ }^{11}$ The treatment produced a rapid and profound benefit for all response variables measured. This was accompanied by a rapid reduction in $\mathrm{C}$ reactive protein (CRP) levels. Clinical improvement was clearly correlated with endoscopic improvement. On the basis of another randomised controlled trial, ${ }^{12}$ infliximab was approved by the health authorities in the United States (FDA) and Europe (EMEA) as a drug for treatment resistant moderate to severe Crohn's disease and fistulising Crohn's disease. However, studies on infliximab in inflammatory bowel disease have not evaluated the effect on associated rheumatological manifestations, such as spondylitis, synovitis, or enthesitis. Moreover, the effect of the compound has not been tested in patients with other types of SpA. Recently, we noted a fast and significant improvement of articular and axial inflammation in four patients with $\mathrm{SpA}$ associated with Crohn's disease treated with infliximab (unpublished observation). Furthermore, preliminary observations in polyarticular psoriatic arthritis $^{13}{ }^{14}$ suggest that $\mathrm{TNF} \alpha$ blockade has a 
beneficial role on articular symptoms. Few data exist about the expression of $\mathrm{TNF} \alpha$ in joints of patients with SpA. However, in sacroiliac joint biopsy specimens from patients with ankylosing spondylitis, an abundant $\mathrm{TNF} \alpha$ message could be found by in situ hybridisation. ${ }^{15}$ Finally, in contrast with SpA, the indication for $\mathrm{TNF} \alpha$ blockade in rheumatoid arthritis has been well documented. ${ }^{16} 17$

The current pilot study was designed as an open-label study to evaluate the efficacy of $\mathrm{TNF} \alpha$ blockade with infliximab in patients with SpA.

\section{Patients and methods \\ STUDY DESIGN}

The study was an open-label, monocentre, 12 week pilot study. The study design included three infusions of infliximab at weeks, 0,2 , and 6 . The study protocol, the information for the patients, and the consent form were approved by the ethics committee of the University Hospital Gent. All patients enrolled in the trial signed an informed consent form before any procedures related to the study were carried out.

\section{PATIENT SELECTION CRITERIA}

Patients had to fulfil the European Spondylarthropathy Study Group criteria for SpA. ${ }^{18}$ Patients were at least 18 years old. For patients of childbearing potential, a negative pregnancy test result and adequate contraception during the study period and for six months after the last infusion were both entry criteria. At the time of enrolment all patients had active SpA. As there are no validated disease activity criteria for the group of $\mathrm{SpA}$ diseases as a whole, this was defined as the presence of at least one swollen joint, one active tendinitis or dactylitis, and/or inflammatory spinal pain (typical "night pain"). Disease modifying drugs, such as sulfasalazine, methotrexate, and cyclosporin, were not allowed during the study, and were discontinued at least four weeks before baseline. Exclusion criteria included serious infections (for example, hepatitis, pneumonia, pyelonephritis) in the previous three months, opportunistic infections within two months of screening, documented HIV infection, proven urogenital or gastrointestinal reactive arthritis, known malignancy, and current signs of severe, progressive, or uncontrolled concomitant disease in the opinion of the investigator. Cardiopulmonary abnormalities were excluded by obtaining a chest radiography and electrocardiogram at screening. Patients who had received an investigational drug within the previous three months, or any therapeutic agent targeted at reducing $\mathrm{TNF} \alpha$ within the previous six months, were also excluded.

\section{CONCURRENT DRUGS}

Patients were allowed to continue nonsteroidal anti-inflammatory drugs or corticosteroids ( $\leqslant 10 \mathrm{mg}$ prednisolone/day), or both, provided that the dosage and schedule regimen was stable for at least four weeks before baseline, and throughout the study. No intra- articular injections of steroids were allowed during the trial.

DRUG ADMINISTRATIONS

Infliximab at a dose of $5 \mathrm{mg} / \mathrm{kg}$ in $250 \mathrm{ml} \mathrm{NaCl}$ $0.9 \%$ was prepared by the hospital pharmacy. The total dose was given over a period of at least two hours. Aseptic procedures were used during the preparation and administration of the study drug. To reduce possible immunogenicity of infliximab it was decided to give three intravenous infusions, which is the current administration schedule for patients with rheumatoid arthritis ${ }^{17}$ : patients received infliximab at weeks 0 (baseline), 2, and 6 .

\section{CLINICAL EVALUATION}

Patients were seen for clinical evaluation at baseline and days $3,7,14,28,42,56,70$, and 84. At these visits the following variables were evaluated: patient global assessment of disease activity (100 $\mathrm{mm}$ visual analogue scale (VAS)), patient assessment of pain (100 mm VAS), doctor global assessment of disease activity (100 mm VAS), erythrocyte sedimentation rate (ESR), and CRP.

In patients with peripheral arthritis an evaluation of duration of morning stiffness (min) and pain (100 mm VAS) of the peripheral joints was made by the patient; tender joint count (68 joints) and swollen joint count (66 joints) were assessed by the doctor.

In patients fulfilling modified New York criteria for ankylosing spondylitis, ${ }^{19}$ axial examination was performed at baseline and days 14, 42, and 84; this comprised a patient and doctor assessment. Tests scored by the patient were sleep disturbance due to night pain $(0=$ not bothered, no pain at all; $1=$ bothered a little, pain is present part of the time, but mild; $2=$ bothered a lot, steady or intermittent pain which usually interferes with sleep; and $3=$ bothered terribly, the night pain is constant, causes marked interference with sleep and the patient is quite miserable); duration of morning stiffness of the spine (min); pain of the spine (100 mm VAS); Bath Ankylosing Spondylitis Disease Activity Index (BASDAI) ${ }^{20}$; Bath Ankylosing Spondylitis Functional Index $(\mathrm{BASFI})^{21}$; and Dougados Functional Index (Dougados FI). ${ }^{22}$ Tests performed by the doctor were clinical assessment of spinal pain $(0=$ no pain on firm palpation percussion, and on extreme motion; no spasm; 1 = slight pain on firm palpation, percussion, or motion; no more than slight limitation of motion; $2=$ moderate pain on moderate palpation, percussion, or motion; no more than slight limitation of motion; 3 = moderate to severe pain on slight palpation, percussion, or slight motion; moderate to severe limitation of motion; and $4=$ extreme pain with inability to withstand even slight palpation or percussion, and essentially no mobility of the spine); Bath Ankylosing Spondylitis Metrology Index (BASMI), ${ }^{23}$ chest expansion, fingers to floor test, occiput to wall test, modified Schober test, cervical rotation, lateral spinal flexion, intermalleolar distance; and an articular index according to Dougados et $a .^{22}$ The extent of skin disease in patients 
Table 1 Demographic and descriptive characteristics of the study group

\begin{tabular}{|c|c|c|c|c|c|}
\hline & Total $(n=21)$ & $A S^{\star}(n=3)$ & $A S+P A^{\star}(n=7)$ & $P_{s} A^{\star}(n=9)$ & $U S p A^{\star}(n=2)$ \\
\hline Age (years) & $49(26-73)$ & $33(26-65)$ & $44(28-59)$ & $49(30-73)$ & $48(39-58)$ \\
\hline $\operatorname{Sex}(M / F)$ & $17 / 4$ & $3 / 0$ & $6 / 1$ & $6 / 3$ & $2 / 0$ \\
\hline Disease duration (years) & $17(1-42)$ & $15(9-40)$ & $17(10-33)$ & $19(1-42)$ & $15(3-28)$ \\
\hline Swollen joint count (0-66) & $3(0-12)$ & 0 & $2(1-4)$ & $9(1-12)$ & $9(8-10)$ \\
\hline Axial morning stiffness (min) & - & $90(60-120)$ & $90(30-240)$ & - & - \\
\hline Axial night pain $(0-3)$ & - & $3(2-3)$ & $3(1-3)$ & - & - \\
\hline Erythrocyte sedimentation rate $(\mathrm{mm} / 1 \mathrm{st} \mathrm{h})$ & $44(10-101)$ & $26(10-74)$ & $44(10-101)$ & $27(13-51)$ & $60(29-92)$ \\
\hline $\mathrm{C}$ reactive protein $(\mathrm{g} / \mathrm{l})$ & $0.046(0.007-0.29)$ & $0.055(0.029-0.064)$ & $0.092(0.007-0.29)$ & $0.034(0.007-0.061)$ & $0.061(0.03-0.091)$ \\
\hline HLA-B27 (+/-) & $14 / 5$ & $3 / 0$ & $6 / 1$ & $4 / 3$ & $1 / 1$ \\
\hline
\end{tabular}

Values are given as median (range).

${ }^{\star} \mathrm{AS}=$ ankylosing spondylitis; AS + PA = ankylosing spondylitis with peripheral arthritis; PsA = psoriatic arthritis; USpA = undifferentiated spondyloarthropathy.

with psoriasis was measured with the Psoriasis Area and Severity Index (PASI) ${ }^{24}$ at baseline and days $14,28,42$, and 84 .

SAFETY EVALUATION

During the infusion and for one hour afterwards, the patient was monitored for adverse effects, and vital parameters (blood pressure, pulse, temperature) were measured every 30 minutes. If the infusion had been well tolerated, the patient was discharged one hour after the end of the infusion. At each visit, patients were asked about side effects, and routine laboratory tests were performed, which consisted of a full blood count with white blood cell differentiation, and biochemical screening including electrolytes, urea, creatinine, total protein, and liver function tests. Urine analysis was performed at screening and at the final visit.

STATISTICAL ANALYSIS

Variables are presented as the median and range. Significance of the change from baseline was measured by the Wilcoxon signed ranks test $(\mathrm{p}<0.05)$.

\section{Results}

Twenty one consecutive patients with treatment resistant, longstanding $\mathrm{SpA}$, fulfilling entry criteria, were enrolled in the study, and treated with infliximab. Table 1 shows demographic and descriptive characteristics of the patients. Patients were classified as having AS with only axial disease $(n=3)$, AS with peripheral arthritis (AS + PA) $(n=7)$, psoriatic arthritis (PsA) ( $n=9)$, and undifferentiated SpA (USpA) $(n=2)$. Nine of the 10 patients with AS were HLA-B27 positive. In the group with PsA eight patients had skin disease. Of the nine patients with PsA, one also fulfilled the modified New York criteria for AS. Thus for evaluation purposes of some variables, the patients were divided into those with peripheral arthritis and/or enthesitis $(n=18)$, and those with axial disease $(n=11)$.

EFFICACY EVALUATION AFTER A SINGLE INFUSION Global assessments

Global assessments were made in all patients $(n=21)$ at days 3,7 , and 14 , and were compared with the baseline value (table 2).

Table 2 Global and peripheral assessments before and at days 3, 7, and 14 after treatment

\begin{tabular}{lllll}
\hline & Baseline & Day 3 & Day 7 & Day 14 \\
\hline Global assessments $(n=21)$ & & & & \\
Patient global $(0-100)$ & $57(27-100)$ & $33(2-81)^{\star \star}$ & $24(2-69)^{\star \star}$ & $23(3-52)^{\star \star}$ \\
Patient pain (0-100) & $70(23-100)$ & $29(4-90)^{\star \star}$ & $23(2-91)^{\star \star}$ & $25(4-61)^{\star \star}$ \\
Doctor global (0-100) & $57(12-79)$ & $33(7-59)^{\star \star}$ & $24(7-37)^{\star \star}$ & $23(5-36)^{\star \star}$ \\
ESR† (mm/1st h) & $44(10-101)$ & $33(7-87)^{\star \star}$ & $13(4-64)^{\star \star}$ & $6(2-30)^{\star \star}$ \\
CRP† (g/l) & $0.046(0.007-0.29)$ & $0.018(0.003-0.152)^{\star \star}$ & $0.004(0-0.015)^{\star \star}$ & $0.003(0-0.01)^{\star \star}$ \\
Peripheral assessments $(n=18)$ & $90(10-300)$ & - & & $5(0-150)^{\star \star}$ \\
Morning stiffness (min) & $75(20-99)$ & - & - & $27(1-49)^{\star \star}$ \\
Pain peripheral joints (0-100) & $6(1-18)$ & $3(0-17)^{\star \star}$ & $1(0-15)^{\star \star}$ & $2(0-11)^{\star \star}$ \\
Tender joint count $(0-68)$ & $3.5(1-12)$ & $1.5(0-10)^{\star}$ & $2(0-5)^{\star \star}$ & $1(0-9)^{\star \star}$ \\
Swollen joint count $(0-66)$ & & & \\
\hline
\end{tabular}

Values are given as median (range).

${ }^{\star} \mathrm{p} \leqslant 0.01 ;{ }^{\star \star} \mathrm{p} \leqslant 0.001$ (determined by Wilcoxon signed ranks test compared with baseline).

tESR = erythrocyte sedimentation rate; CRP $=\mathrm{C}$ reactive protein

Table 3 Assessments of patients with axial disease $(n=11)$ before and at days 14,42 , and 84 after treatment

\begin{tabular}{|c|c|c|c|c|}
\hline & Baseline & Day 14 & Day 42 & Day 84 \\
\hline Night pain $(0-3)$ & $3(1-3)$ & $1(0-2)^{\star}$ & $0(0-2)^{\star}$ & $1(0-1)^{\star}$ \\
\hline Morning stiffness ( $\min$ ) & $90(30-240)$ & $15(0-120)^{\star}$ & $10(0-120)^{\star}$ & $5(0-120)^{\star}$ \\
\hline Pain spine $(0-100)$ & $57(4-95)$ & $20(3-68) \dagger$ & $15(0-80) \dagger$ & $11(1-60)^{\star}$ \\
\hline BASDAI $\ddagger(0-100)$ & $62.4(28.8-82.4)$ & $18.3(5.0-60.6)^{\star}$ & $9.5(3.2-59.5)^{\star}$ & $11.3(1.2-44.0)^{\star}$ \\
\hline BASFI $\neq(0-100)$ & $77.4(9.9-94.2)$ & $29.4(1.8-71.6)^{\star}$ & $13.1(4.1-66.5)^{\star}$ & $22.3(1.0-63.2)^{\star}$ \\
\hline Dougados FI $(0-40)$ & $21(7-31.5)$ & $12(3-24)^{\star}$ & $7.5(2.0-22.0)^{\star}$ & $8.5(0.5-21.0)^{\star}$ \\
\hline Spinal pain $(0-3)$ & $2(0-3)$ & $1(0-3)^{\mathrm{NS}}$ & $0(0-3) \dagger$ & $0(0-2) \dagger$ \\
\hline BASMI $\neq(0-10)$ & $5(3-9)$ & $5(0-9) \dagger$ & $5(1-9) \dagger$ & $5(1-9) \dagger$ \\
\hline Occiput to wall $(\mathrm{cm})$ & $12(3.7-21.5)$ & $9.5(0-21.0) \dagger$ & $9(2.5-21.0)^{\star}$ & $7.7(2.5-22.0)^{\star}$ \\
\hline Chest expansion $(\mathrm{cm})$ & $1.8(1.5-3.2)$ & $3.5(1.0-5.5) \dagger$ & $3(1.8-5.0)^{\star}$ & $3.8(1.7-5.5)^{\star}$ \\
\hline Fingers to floor $(\mathrm{cm})$ & $24(5.5-38.0)$ & $18(0-34.0)^{\star}$ & $17.5(0-35.4)^{\star}$ & $15(0-20.3)^{\star}$ \\
\hline Dougados articular index $(0-30)$ & $6(1-15)$ & $2(0-7)^{\star}$ & $2(0-3)^{\star}$ & $0(0-4)^{\star}$ \\
\hline
\end{tabular}

Values are given as median (range)

$t p \leqslant 0.05 ;{ }^{\star} p \leqslant 0.01 ; \mathrm{NS}=$ not significant (determined by Wilcoxon signed ranks test compared with baseline).

†BASDAI = Bath Ankylosing Spondylitis Disease Activity Index; BASFI = Bath Ankylosing Spondylitis Functional Index; Dougados FI = Dougados Functional Index; BASMI = Bath Ankylosing Spondylitis Metrology Index. 
Table 4 Global and peripheral assessments before and at days 14, 42, and 84 after treatment

\begin{tabular}{lllll}
\hline & Baseline & Day 14 & Day 42 & Day 84 \\
\hline Global assessments $(n=21)$ & & & & \\
Patient global $(0-100)$ & $57(27-100)$ & $23(3-52)^{\star \star}$ & $11(1-45)^{\star \star}$ & $10(1-73)^{\star \star}$ \\
Patient pain (0-100) & $70(23-100)$ & $25(4-61)^{\star \star}$ & $13(1-50)^{\star \star}$ & $10(1-86)^{\star \star}$ \\
Doctor global (0-100) & $57(12-79)$ & $23(5-36)^{\star \star}$ & $11(1-45)^{\star \star}$ & $10(5-75)^{\star \star}$ \\
ESR† (mm/1st h) & $44(10-101)$ & $6(2-30)^{\star \star}$ & $5(2-38)^{\star \star}$ & $4(2-68)^{\star \star}$ \\
CRP† (g/l) & $0.046(0.007-0.29)$ & $0.003(0-0.01)^{\star \star}$ & $0.002(0-0.017)^{\star \star}$ & $0.006(0-0.155)^{\star \star}$ \\
Peripheral assessments (n=18) & & & & $5(0-60)^{\star \star}$ \\
Morning stiffness (minutes) & $90(10-300)$ & $5(0-150)^{\star \star}$ & $10(0-150)^{\star}$ & $12(0-84)^{\star \star}$ \\
Pain peripheral joints (0-100) & $75(20-99)$ & $27(1-49)^{\star \star}$ & $10,5(0-31)^{\star \star}$ & $0(0-5)^{\star \star}$ \\
Tender joint count (0-68) & $6(1-18)$ & $2(0-11)^{\star \star}$ & $0(0-7)^{\star \star}$ & $0(0-7)^{\star \star}$ \\
Swollen joint count $(0-66)$ & $3.5(1-12)$ & $1(0-9)^{\star \star}$ & $0(0-7)^{\star \star}$ & \\
\hline
\end{tabular}

Values are given as medians (range).

${ }^{\star} \mathrm{p} \leqslant 0.01 ;{ }^{\star \star} \mathrm{p} \leqslant 0.001$ (determined by Wilcoxon signed ranks test compared with baseline).

†ESR $=$ erythrocyte sedimentation rate; $\mathrm{CRP}=\mathrm{C}$ reactive protein.

From day 3 onwards, there was a statistically significant decrease for all variables measured, and this was maintained up to day 14 .

Peripheral assessments

Peripheral assessments were made in 18 patients with at least one peripheral arthritis or enthesitis (table 2). Morning stiffness and pain in the peripheral joints were evaluated at day 14 and had decreased significantly compared with baseline. A significant reduction of tender and swollen joint count was seen from day 3 onwards.

Axial assessments

Table 3 shows the results of assessments of patients with axial disease. All variables, both from the patient's and the doctor's part of the assessment, improved significantly with the exception of spinal pain, assessed by the doctor $(\mathrm{p}=0.052)$. The BASMI improved significantly, as did other variables which are not included in this index, such as occiput to wall distance, chest expansion, and fingers to floor distance. Of the measurements that are included in the BASMI, only the modified Schober test $(\mathrm{p}=0.052)$ and intermalleolar distance $(p=0.286)$ showed no significant improvement.

Psoriasis skin disease

The skin disease in eight patients with PsA was evaluated using the PASI index. The median
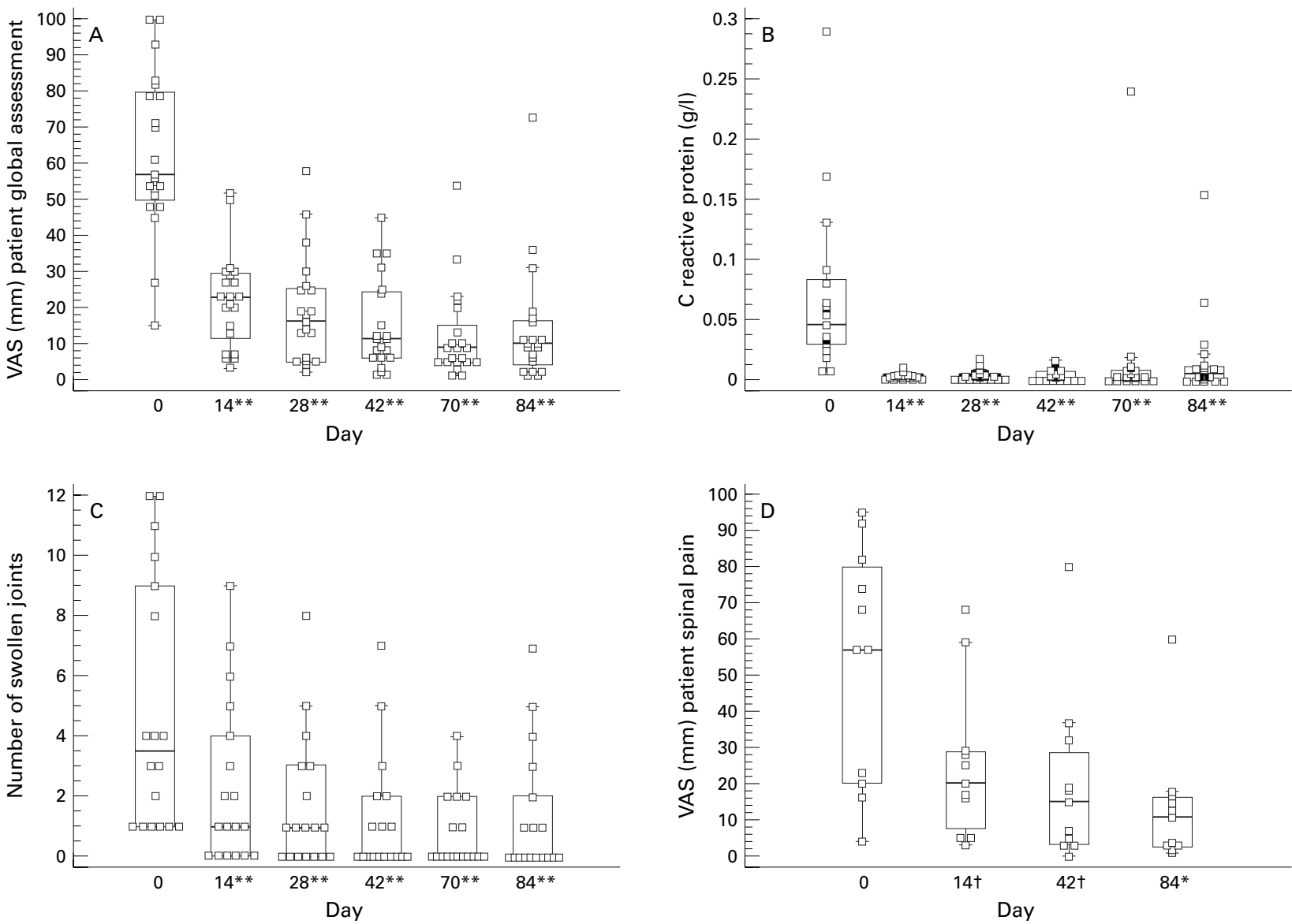

Figure 1 Evolution of patient assessments over time. The box and whisker plots show the median value (horizontal line) and range (first to third quartiles in boxes, $98 \%$ of values between enclosed bars, individual values indicated by single dot) of the chosen parameter (y axis) over time (days). Significance (p) was calculated by Wilcoxon signed ranks test. $t p \leqslant 0.05 ;{ }^{*} \leqslant 0.01$; ${ }^{\star *} p \leqslant 0.001$. (A) Patient global assessment (100 mm visual analogue scale (VAS)); (B) $C$ reactive protein $(g / l)$; (C) swollen joint count; (D) spinal pain assessment (100 mm VAS). 
score of these patients at baseline was 0.72 (range $0.12-15.8$ ). At day 14 this score had significantly decreased to $0.445(0.05-9.22)$ $(\mathrm{p}=0.012)$.

Analysis of subgroups

All variables (global, peripheral, and axial) were evaluated in the different subgroupsnamely, AS, AS with peripheral arthritis, PsA, and USpA (data not shown). There were no arguments that one of the subgroups responded in a different way to the treatment with infliximab. In five patients with peripheral arthritis, there was an increase in the number of swollen joints at day 14 compared with day 7 . Four of these patients had PsA; however, this slight increase was not statistically significant.

EFFICACY EVALUATION AT THREE MONTHS Global, peripheral, and axial assessments

All patients received a second and a third infusion at weeks 2 and 6 respectively. Efficacy evaluations, as described above, were performed every two weeks, up to day 84 (six weeks after the last infusion). Tables 3 and 4 show the results obtained: all variables remained statistically significant up to day 84 compared with baseline. Figure 1 shows the evolution of selected assessments over time.

Psoriasis skin disease

The marked improvement in the PASI score, noted at day 14, was maintained throughout the study: median values for the PASI score were 0.445 (range 0.05-9.22), 0.16 (range $0.03-1.81$ ), and 0.105 (range 0.03-2.28) at respectively days 14,42 , and 84 . All these values were significant compared with baseline with a $\mathrm{p}$ value $\leqslant 0.05$.

SAFETY EVALUATION AND ADVERSE DRUG

REACTIONS

No patients were withdrawn from the study owing to adverse events. No adverse effects related to infusion were noted. Vital parameters remained within the normal range during and for one hour after infusion. Laboratory tests were performed at days 3, 7, and 14, and from then on every two weeks up to day 84 , and were compared with baseline: no significant changes were seen. Twelve patients reported minor side effects: these comprised nausea $(n=3)$, dizziness $(n=2)$, headache $(n=2)$, fatigue $(n=2)$, diarrhoea $(n=1)$, palpitations $(n=1)$, and a burning feeling in the eyes $(n=1)$. None of these caused interruption or discontinuation of the treatment.

\section{Discussion}

The goal of our pilot study was to determine the short term efficacy and safety of infliximab in patients with $\mathrm{SpA}$; this was an open-label study of 21 patients. A dose of $5 \mathrm{mg} / \mathrm{kg}$ was chosen based on the experience in patients with Crohn's disease. Personal case observations from our group suggested that in patients with Crohn's disease and associated SpA, this dose was active on the articular symptoms (peripheral and axial).
All the measured variables improved significantly after the first infusion. The drug acted quickly: for global and peripheral assessments the improvement was statistically significant from day 3 onwards. Axial assessment was not performed before day 14: from then on, we saw a significant improvement in both patient and doctor assessment of axial pain, stiffness, and mobility, as measured by different tests and the global BASMI. Modified Schober test $(\mathrm{p}=0.052)$, intermalleolar distance $(\mathrm{p}=0.286)$, and spinal pain assessed by the doctor $(p=0.052)$ were the only assessments that failed to reach statistical significance at day 14 ; however, all variables became significant with a $\mathrm{p}$ value $\leqslant 0.05$ from day 42 onwards.

Moreover, measures of functional impairment, such as the BASFI and the Dougados FI, improved significantly from day 14 onwards. Skin disease was evaluated in only eight patients with PsA; nevertheless, there was a statistically significant improvement of the PASI score at day 14 compared with baseline, and this was maintained up to day 84 . The infusion was well tolerated, and no major adverse effects were reported. Laboratory tests for safety stayed within the normal range during the study; inflammatory variables decreased significantly from day 3 onwards. No definite conclusions can be drawn about the duration of the effect of the proposed loading dose regimen of three infusions with infliximab in SpA: all measured variables showed a statistically significant improvement, which was maintained up to day 84. All patients are still in follow up to report the longer term efficacy of this induction regimen.

In interpreting these data, we have to remember that this is an open study on a small group of patients. However, looking at the characteristics of the patient group, it can be seen that all the patients had longstanding and active disease: median values for patient and doctor global assessment, and functional indices such as BASFI and Dougados FI, are all high at baseline. Contrary to rheumatoid arthritis, a low joint count is not necessarily an indicator of less active disease in SpA. Likewise, ESR and CRP are not considered as measures of disease activity in SpA, but it is of interest that the baseline values are relatively high, and that there is a significant decrease after a single infusion of infliximab.

Three interesting points can be made. Firstly, the drug seems to have a profound effect on all disease variables measured in patients with different subtypes of $\mathrm{SpA}$ : this effect on global disease, peripheral and axial manifestations, and on skin disease is remarkable, as other treatments, such as sulfasalazine, for example, seem to have an effect that is limited to peripheral disease without significant effect on axial disease. ${ }^{25}$ Secondly, the onset of improvement is fast with most variables reaching statistical significance already by day 3 . Finally, using a loading dose regimen of three infusions (weeks 0,2 , and 6), it was possible to maintain statistically significant clinical improvement up to day 84 (six weeks after the last infusion). 
Our data indicate that $\mathrm{TNF} \alpha$ plays a prominent role in the pathogenesis and disease manifestations of SpA. However, no conclusion can be drawn about the mechanism of action of $\mathrm{TNF} \alpha$ blockade in this disease group. This effect might be mediated through a systemic action of the drug, or by a local effect at the site of the joint or even the gut mucosa. ${ }^{26}$ Since the beneficial effect of infliximab on Crohn's disease has been proved, ${ }^{10-12}$ and there is a close relation between the gut and the synovium, ${ }^{3-5}$ possibly, infliximab has an influence on the subclinical involvement of the gut in patients with $\mathrm{SpA}$.

The data question the classical paradigm of interference of $\mathrm{TNF} \alpha$ blockade with the balance between $\mathrm{T}$ helper 1 and $\mathrm{T}$ helper 2 cytokines. The beneficial effects seen in Crohn's disease and rheumatoid arthritis have been associated with the proposed $\mathrm{T}$ helper 1 nature of these diseases. Data on cytokine profiles in $\mathrm{SpA}$ are scarce, but point more to a $\mathrm{T}$ helper 2 profile. ${ }^{27}{ }^{28}$ Yet, we observe here a clear beneficial effect of TNF $\alpha$ blockade on the joint disease in SpA.

Our clinical data from this short term openlabel pilot study of 21 patients with different types of $\mathrm{SpA}$ warrant further confirmation of the beneficial effects of $\mathrm{TNF} \alpha$ blockade in larger, controlled, double blind studies.

We thank Mrs A Herssens who took care of the patients during the infusions. Filip Van den Bosch and Elli Kruithof contributed equally to this study. The authors are indebted to Schering Plough and Centocor (F Cornillie) for the supply of the study drug. Dominique Baeten is an FWO-Vlaanderen research assistant. This work was supported by a concerted action grant GOA 96001 of the University of Gent, Belgium.

1 Wright V. Seronegative polyarthritis-a unified concept. Arthritis Rheum 1978;21:618-33.

2 Mielants H, Veys EM, Cuvelier C, De Vos M. Ileocolonoscopic findings in seronegative spondylarthropathies. $\mathrm{Br}$ Rheumatol 1988;27(suppl 2):95-105.

3 Mielants H, Veys EM, De Vos M, Cuvelier C, Goemaere S, De Clercq L, et al. The evolution of the spondyloarthropathies in relation to gut histology. I. Clinical aspects. J Rheumatol 1995;22:2266-72.

4 De Vos M, Mielants H, Cuvelier C, Elewaut D, Veys E. Long-term evolution of gut inflammation in patients with spondyloarthropathy. Gastroenterology 1996;110:1696703 .

5 Mielants H, Veys EM, Cuvelier C, De Vos M, Goemaere S, De Clercq L, et al. The evolution of spondyloarthropathies in relation to gut histology. III. Relation between gut and joint. J Rheumatol 1995;22:2273-8.

6 Dick AP, Grayson MJ, Carpenter RC, Petrie A. Controlled trial of sulfasalazine in the treatment of ulcerative colitis Gut 1964;5:437-42.

7 Van Hees PA, Van Lier HJ, Van Elteren PH, Driessen M, Van Hogezand RA, Ten Velde GP, et al. Effect of sulphasalazine in patients with active Crohn's disease: a controlled double-blind study. Gut 1981;22:404-9.

8 Dougados $M$, van der Linden $S$, Leirisalo-Repo $M$, Huitfeldt B, Juhlin R, Veys E, et al. Sulfasalazine in the treatment of spondylarthropathy: a randomized, multicenter, double-blind, placebo-controlled study. Arthritis Rheum 1995;38:618-27.
9 Knight DM, Trinh H, Le J, Siegel S, Shealy D, McDonough $\mathrm{M}$, et al. Construction and initial characterization of a mouse-human chimeric anti-TNF antibody. Mol Immunol 1993;30:1443-53.

10 Van Dullemen HM, Van Deventer SJ, Hommes DW, Bijl HA, Jansen J, Tytgat GN, et al. Treatment of Crohn 's disease with anti-tumor necrosis factor chimeric monoclonal antibody (cA2). Gastroenterology 1995;109:129-35.

11 Targan SR, Hanauer SB, Van Deventer SJ, Mayer L, Present $\mathrm{DH}$, Braakman $\mathrm{T}$, et al. A short-term study of chimeric monoclonal antibody cA2 to tumor necrosis factor alpha for Crohn's disease. Crohn's Disease cA2 Study Group. N Engl J Med 1997;337:1029-35.

12 Present DH, Rutgeerts P, Targan S, Hanauer SB, Mayer L, van Hogezand RA, et al. Infliximab for the treatment of fistulas in patients with Crohn's disease. N Engl J Med 1999; 340:1398-405.

13 Antoni C, Dechant C, Lorenz H, Olgivie A, KaldenNemeth D, Kalden J, et al. Successful treatment of severe psoriatic arthritis with infliximab [abstract]. Arthritis Rheum 1999;42(suppl):A1801.

14 Mease P, Goffe B, Metz J, Vanderstoep A. Enbrel ${ }^{\circledR}$ (etanercept) in patients with psoriatic arthritis and psoriasis [abstract]. Arthritis Rheum 1999;42 (suppl):A1835.

15 Braun J, Bollow M, Neure L, Seipelt E, Seyrekbasan F, Herbst $\mathrm{H}$, et al. Use of immunohistologic and in situ hybridization techniques in the examination of sacroiliac joint biopsy specimens from patients with ankylosing spondylitis. Arthritis Rheum 1995;38:499-505.

16 Kavanaugh AF. Anti-tumor necrosis factor- $\alpha$ monoclonal antibody therapy for rheumatoid arthritis. Rheum Dis Clin North Am 1998;24:593-614.

17 Maini RN, Breedveld FC, Kalden JR, Smolen JS, Davis D, Macfarlane JD, et al. Therapeutic efficacy of multiple intravenous infusions of anti-tumor necrosis factor $\alpha$ monoclonal antibody combined with low-dose weekly methotrexate in rheumatoid arthritis. Arthritis Rheum 1998;41: trexate in

18 Dougados M, van der Linden S, Juhlin R, Huitfeldt B, Amor B, Calin A, et al. The European Spondylarthropathy Study Group preliminary criteria for the classification of spondylarthropathy. Arthritis Rheum 1991;34:1218-27.

19 van der Linden S, Valkenburg HA, Cats A. Evaluation of diagnostic criteria for ankylosing spondylitis. A proposal for modification of the New York criteria. Arthritis Rheum 1984;27:361-8

20 Garrett S, Jenkinson T, Kennedy LG, Whitelock H, Gaisford P, Calin A. A new approach to defining disease status in ankylosing spondylitis: the Bath Ankylosing Spondylitis Disease Activity Index. J Rheumatol 1994;21: 2286-91

21 Calin A, Garrett S, Whitelock H, Kennedy LG, O'Hea J, Mallorie $\mathrm{P}$, et al. A new approach to defining functional ability in ankylosing spondylitis: the development of the Bath Ankylosing Spondylitis Functional Index. J Rheumatol 1994;21:2281-5.

22 Dougados M, Gueguen A, Nakache JP, Nguyen M, Mery C, Amor B. Evaluation of a functional index and an articular index in ankylosing spondylitis. J Rheumatol 1988;15: $302-7$.

23 Jenkinson TR, Mallorie PA, Whitelock HC, Kennedy LG, Garrett SL, Calin A. Defining spinal mobility in ankylosing spondylitis (AS). The Bath AS Metrology Index. J Rheumatol 1994;21:1694-8.

24 Fredriksson T, Pettersson U. Severe psoriasis - oral therapy with a new retinoid. Dermatologica 1978;157:238-44.

25 Clegg DO, Reda DJ, Abdellatif M. Comparison of sulfasalazine and placebo for the treatment of axial and peripheral articular manifestations of the seronegative spondylarthropathies: a Department of Veterans Affairs cooperative study. Arthritis Rheum 1999;42:2325-9.

26 De Keyser F, Van Damme N, De Vos M, Mielants H, Veys EM. Opportunities for immune modulation in the spondyloarthropathies with special reference to gut inflam-

27 Simon AK, Seipelt E, Sieper J. Divergent T-cell cytokine patterns in inflammatory arthritis. Proc Natl Acad Sci USA 1994;91:8562-6.

28 Yin Z, Braun J, Neure L, Wu P, Liu L, Eggens U, et al. Crucial role of interleukin-10/interleukin-12 balance in the regulation of the type $2 \mathrm{~T}$ helper cytokine response in reactive arthritis. Arthritis Rheum 1997;40:1788-99. 